\title{
Selected Properties of Flat-Pressed Wood-Polymer Composites for High Humidity Conditions
}

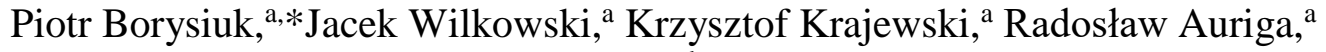 \\ Adrian Skomorucha, ${ }^{a}$ and Alicja Auriga ${ }^{b}$
}

\begin{abstract}
This study investigated the possibility of applying flat-pressed woodpolymer composites in conditions of high humidity. The experiment involved three variants of wood-polymer composite panels $16 \mathrm{~mm}$ thick, and $680 \mathrm{~kg}$ per $\mathrm{m}^{3}$ density. The wood particles were bonded with polyethylene. The share of polyethylene in the core layer was fixed at $50 \%$, while in the face layers the content was varied $(40 \%, 50 \%$, or $60 \%)$. The following parameters were examined: modulus of rupture (MOR), modulus of elasticity (MOE), internal bond (IB), screw holding (SH), thickness swelling (TS), water absorption (WA), susceptibility to drilling and milling, wettability and surface free energy, and resistance to mold. The results were compared to particleboard glued with urea-formaldehyde resin. The wood-polymer composite had lower MOR and MOE values and similar IB and $\mathrm{SH}$ values. The panels indicated a remarkably higher water resistance (lower TS and WA values) with good surface wettability and high resistance to mold fungi. Additionally, the composites were easier to machine, e.g. drilling or milling, in comparison to standard particleboards.
\end{abstract}

Keywords: Wood-polymer composite; Mechanical and physical properties; Machining; Resistance to mold

Contact information: a: Warsaw University of Life Sciences - SGGW, Institute of Wood Sciences and

Furniture, ul. Nowoursynowska 159, 02-776 Warsaw, Poland; b: West Pomeranian University of

Technology Szczecin, Faculty of Environmental Management and Agriculture, ul. Stowackiego 17, 71-434

Szczecin, Poland; *Corresponding author: Piotr_borysiuk@sggw.pl

\section{INTRODUCTION}

The range of wood-polymer composites (WPC) applications in new material solutions has been continually expanding. Aside from the standard WPC composites produced by extrusion or injection, the concept of the bonding of wood chips with use of thermoplastics has been developed. Research conducted in this field indicates the possibility of producing boards with favorable operational and quality parameters using methods similar to wood-based board pressing technology (Youngquist et al. 1994, 1995; Boeglin et al. 1997; Borysiuk 2004, Borysiuk et al. 2004, 2006). The strength of woodpolymer composites is determined by the quantitative share of wood and thermoplastic particles, the size of the wood particles, the type of thermoplastic, the addition of bonding substances, and the manufacturing methods (Stark and Berger 1997; Błędzki and Faruk 2004). The composites achieve optimal resistance to bending forces at a wood particle content in the range of 40 to 60\% (Stark and Berger 1997; Borysiuk et al. 2004; Chen et al. 2006; Djiporovic et al. 2006; Borysiuk et al. 2008). In general, WPC composites have lower MOR and MOE values and comparable tensile and compressive strength values. An important advantage of wood-polymer composites over other wood-based panels is their water resistance (Falk et al. 1999; Sellers et al. 2000). The hydrophobic properties deteriorate with the increase in the proportion of wood particles in the composite 
(Zajchowski et al. 2005) and the increase in porosity of its structure (e.g., as a result of foaming). Along with the increasing humidity, WPC composites are more susceptible to attack by both home-grown fungi (basidiomycetes) and mold fungi. The degradation effect is dependent on the weight of wood particles, their size, and the species from which they have been manufactured, as well as from the possible use of other additives (Verhey and Laks 2002; Barton-Pudlik et al. 2017).

The appropriate selection of materials to produce elements such as bathroom furniture, is important due to their cyclic contact with high humidity air, temperature variability, as well as frequent contact of the material with liquid water. Wood-based materials selected for these constructions must meet several requirements, the most important being resistance to water. Wood-based materials show high hygroscopicity, which results in the free exchange of water vapor contained in the material with the environment. The use of traditional boards with resistance to water does not guarantee sufficient protection against the destructive effects of moisture and related degradation factors (Thoemen et al. 2010; Niemz and Sonderegger 2017). A good solution for applications in an environment with high relative humidity (e.g., as elements of bathroom or kitchen furniture) may be wood-polymer composites.

The research evaluates selected properties determining the applicability of woodpolymer composites in production of furniture elements exposed to high humidity or liquid water.

\section{EXPERIMENTAL}

\section{Materials}

Tests were carried out using industrial coniferous particles applied to the face and core layers of the particleboards. The wood particles moisture content was $8 \%$. The panels fractional composition is shown in Table 1.

Table 1. The Fractional Composition of Particles Used in this Study

\begin{tabular}{|c|c|c|c|}
\hline \multirow{2}{*}{$\begin{array}{c}\text { Fraction } \\
(\mathrm{mm})\end{array}$} & \multicolumn{2}{|c|}{ Wractional composition (\%) } \\
\cline { 2 - 3 } & Face layer & Core layer & \multirow{2}{*}{ Thermoplastic particles } \\
\cline { 2 - 4 } & 13.0 & - & 0.2 \\
\hline 6.0 & 19.0 & - & 5.7 \\
\hline 4.0 & 51.0 & 0.6 & 37.3 \\
\hline 2.0 & 13.0 & 14.3 & 39.7 \\
\hline 1.25 & 2.6 & 25.5 & 4.7 \\
\hline 1.00 & 1.0 & 30.0 & 8.4 \\
\hline 0.63 & 0.2 & 11.4 & 0.9 \\
\hline 0.49 & 0.1 & 7.8 & 0.9 \\
\hline 0.385 & 0.1 & 10.4 & 2.2 \\
\hline$<0.385$ & \multicolumn{2}{c}{} \\
\hline
\end{tabular}

Post-consumer HDPE polyethylene obtained from used film and packaging was applied in the tests. The raw material was ground to a similar size as the particles used in the face and core layers, respectively. Grinding of the thermoplastic was carried out using a laboratory mill. The average melting point of polyethylene was $120{ }^{\circ} \mathrm{C}$. Due to the manufacturing method of the boards (cold forming), similarly to Rahman et al. (2013) and Lyutyy et al. (2018) no compatibilizer was applied. 


\section{Boards}

A three-layer wood-polymer board with dimensions of 330 by 330 by $16 \mathrm{~mm}^{3}$ and a density of $680 \mathrm{~kg}$ per $\mathrm{m}^{3}$ was produced. Individual panel variants were characterized by a variable contribution of thermoplastics in the face layers (Table 2). The reference material was a particleboard glued with UF resin. Commercially available urea-formaldehyde resin with a $\mathrm{U}$ per $\mathrm{F}$ molar ratio equal to 1 to $1.2,65 \mathrm{wt} \%$ solids content, and a viscosity of 230 $\mathrm{MPa}$ at a temperature of $20{ }^{\circ} \mathrm{C}$ was used as the binder.

Table 2. Characteristics of Panel Construction

\begin{tabular}{|c|c|}
\hline Parameters & Value \\
\hline Face layers contribution & $34 \%$ \\
\hline Wood-polymer composites (variant A, B, and C) & $50 \%$ \\
\hline Contribution of polyethylene in the core layers & \\
\hline Contribution of polyethylene in the face layers & $40 \%$ \\
\hline Variant A & $50 \%$ \\
\hline Variant B & $60 \%$ \\
\hline Variant C \\
\hline Particleboards glued with UF resin - variant D \\
\hline Degree of sealing of core layers \\
\hline Degree of sealing of the face layers \\
\hline
\end{tabular}

The appropriate proportions of raw materials (thermoplastic and wood particles) for wood-polymer composites were cold mixed. The mats were then formed manually from the obtained mixtures. The boards were manufactured in an electrically heated single-shelf laboratory press. The pressing parameters are presented in Table 3. In the first stage, the mats were hot pressed. After plasticizing the polyethylene, the mats were transferred into the cold press for cooling. Hot and cold pressing was carried out using spacers to determine the thickness of the plates. Finally, the manufactured WPC boards were air-conditioned for 7 days under laboratory conditions $\left(20 \pm 2{ }^{\circ} \mathrm{C}\right.$ and $65 \pm 5 \%$ humidity).

Table 3. Parameters for Pressing the Plates

\begin{tabular}{|c|c|c|}
\hline Parameters & Variant A, B, and C & Variant D \\
\hline Maximum specific pressure & $2.5 \mathrm{MPa}$ & $2.5 \mathrm{MPa}$ \\
\hline Temperature of hot pressing & $200^{\circ} \mathrm{C}$ & $200^{\circ} \mathrm{C}$ \\
\hline Temperature of cold pressing & $20^{\circ} \mathrm{C}$ & - \\
\hline Time of hot pressing & $300 \mathrm{~s}$ & $288 \mathrm{~s}$ \\
\hline Time of cold pressing & $300 \mathrm{~s}$ & - \\
\hline
\end{tabular}

\section{Mechanical and Physical Properties}

Several physical and mechanical properties of the boards were tested in this study. The density was tested according to the EN 323 (1999) standard and the density profile using the Laboratory Density Analyzer DAX GreCon. The density measurement was made every $0.02 \mathrm{~mm}$ at a measurement speed of $0.05 \mathrm{~mm}$ per s. The modulus of rupture (MOR) and modulus of elasticity (MOE) were tested according to the EN 310 (1994) standard. The internal bonding (IB) was tested according to the EN 319 (1999) standard. The screw holding (SH) was tested according to the EN 320 (2011) standard. Thickness swelling (TS) and water absorption (WA) after immersion in water for $2 \mathrm{~h}$ and $24 \mathrm{~h}$ were tested according to the EN 317 (1999) standard. Every test included ten replicates of each variant. Additionally, the susceptibility to drilling and milling, contact angle and surface free 
energy, and resistance to biodegradation were evaluated for the manufactured panels.

\section{Susceptibility to Drilling and Milling}

Plate machinability tests were carried out using a Busellato Jet $130 \mathrm{CNC}$ machining center (Casadei-Busellato, Thiene, Italy). Through-hole drilling (throughout the entire thickness of the plate) was done with a new, $8 \mathrm{~mm}$ diameter, single-edge, polycrystalline DPI diamond drill (Leitz, GmbH and Co. KG, Stuttgart, German). The rotational speed was set to $6000 \mathrm{rpm}$, the feed speed was set to $1.2 \mathrm{~m}$ per min, and the feed per revolution was set to $0.2 \mathrm{~mm}$. During drilling, $F_{\mathrm{z}}$ axial force signals were recorded using a Kistler 9345A piezoelectric force sensor (Kistler Group, Winterthur, Switzerland) with a sampling frequency of $12 \mathrm{kHz}$. For each variant, ten cuts were made. The RMS of axial force signals was evaluated.

A Faba single-edge milling head (Faba S.A., Baboszewo, Poland) with a $40 \mathrm{~mm}$ diameter WC-Co cemented carbide knife was used for milling. During the test, grooves 40 $\mathrm{mm}$ wide (tool diameter) and $5 \mathrm{~mm}$ deep were milled. The rotational speed was set to $18000 \mathrm{rpm}$, the feed speed was set to $2.7 \mathrm{~m}$ per min, and the feed per revolution was set to $0.15 \mathrm{~mm}$. Two components of cutting force were recorded during milling $\left(F_{\mathrm{x}}\right.$ was in accordance with the tool feed direction, and $F_{\mathrm{y}}$ was perpendicular to $F_{\mathrm{x}}$ ) using a Kistler piezoelectric force sensor with a sampling frequency of $12 \mathrm{kHz}$. The resultant cutting force $F_{\mathrm{w}}$ (geometric sum of the vectors $F_{\mathrm{x}}$ and $F_{\mathrm{y}}$ ) was determined based on two perpendicular components. For each variant, seven cuts were made. The mean value of the feed force signals was evaluated.

\section{Wettability (Contact Angle) and Surface Free Energy}

The contact angle $(\theta)$ was based on the sessile drop method and performed on a Phoenix 300 (Surface Electro Optics, Suwon City, Korea) contact angle analyzer, equipped with microscopic lenses and a digital camera. The distilled water and di-iodo-methane were used as reference liquids for the wettability calculations. The angles were determined $60 \mathrm{~s}$ after the drops of liquid were applied onto the surface of the reference (the water). For each type of board (including the right-side A and left side B), ten droplets were measured.

The surface free energy was assayed according to the Owens-Wendt (1969) method. The method consists in determining the contact angles for two measuring liquids (water and di-iodo-methane), and the free surface energy $\left(\gamma_{\mathrm{s}}\right)$ is equal to the sum of dispersion $\left(\gamma_{\mathrm{sd}}\right)$ and polar $\left(\gamma_{\mathrm{sp}}\right)$ components (Wolkenhauer et al. 2009).

\section{Resistance to Molds}

The resistance to mold was evaluated using the test specimens of dimensions 50 by 50 by $16 \mathrm{~mm}^{3}$. The test samples were superficially sterilized by spraying all surfaces with $70 \%$ ethanol. They were placed in sterile glass vessels for $24 \mathrm{~h}$ at $65^{\circ} \mathrm{C}$. After cooling the samples for the next $24 \mathrm{~h}$, they were exposed to pure cultures of Trichoderma virens (strain BAM 34) fungus (growing on $2 \%$ MEA nutrient medium (OXOID)).

The study was carried out in petri dishes with a diameter of $200 \mathrm{~mm}$ and a height of $30 \mathrm{~mm}$. Inoculation was performed on the surface of the nutrient medium using fungus by spraying the spore suspension. The samples were immediately placed in vessels. Four samples were placed in each vessel, namely one sample from each WPC variant (A was $40 \%$, B was $50 \%$, and C was $60 \%$ polymer content) and one control sample (D was $0 \%$ polymer content). The samples of materials were placed directly on the nutrient agar medium to ensure good moisture saturation. 
The growth of fungus was conducted in incubator chambers for 22 days at $26^{\circ} \mathrm{C}$. The degree of fungus overgrowing was determined periodically by taking high resolution laboratory photos, while using the cabinet station for documentation purposes. The degree of mycelium development on the samples was expressed as a percentage of the area covered in relation to the total upper surface of samples. The percentage value overgrowth of samples was determined with an accuracy of up to $5 \%$ with Image J2 - Fiji v1.52i image analysis software (Schindelin et al. 2012; Tinevez et al. 2017).

The resistance of the materials tested with the $T$. virens fungus was presented graphically by comparing the dynamics of mycelium growth on samples with different contents of the WPC polymer.

\section{Statistical Analysis}

Statistical analysis of the results was carried out using Statistica 13 (TIBCO Software Inc.) The analysis of variance (ANOVA) was used to test $(\alpha=0.05)$ for significant differences between factors. A comparison of the means was performed using a Tukey test with $\alpha$ equal to 0.05 .

\section{RESULTS AND DISCUSSION}

\section{Mechanical and Physical Properties}

The average density of the manufactured panels ranged between 699 to $723 \mathrm{~kg}$ per $\mathrm{m}^{3}$. The density profiles of individual panel variants were characterized by a typical Ushaped course (Fig. 1). There were no significant differences between the course of density profiles for individual panel variants. Regardless of the panel variant, the differences between the densities of the face and core layers were in the range of 224 to $296 \mathrm{~kg} \mathrm{per} \mathrm{m}^{3}$. Wong et al. (1998, 1999, 2003) and Treusch et al. (2004) reported that the density distribution is clearly correlated with the basic properties of particleboard, such as the MOR, MOE, and IB.

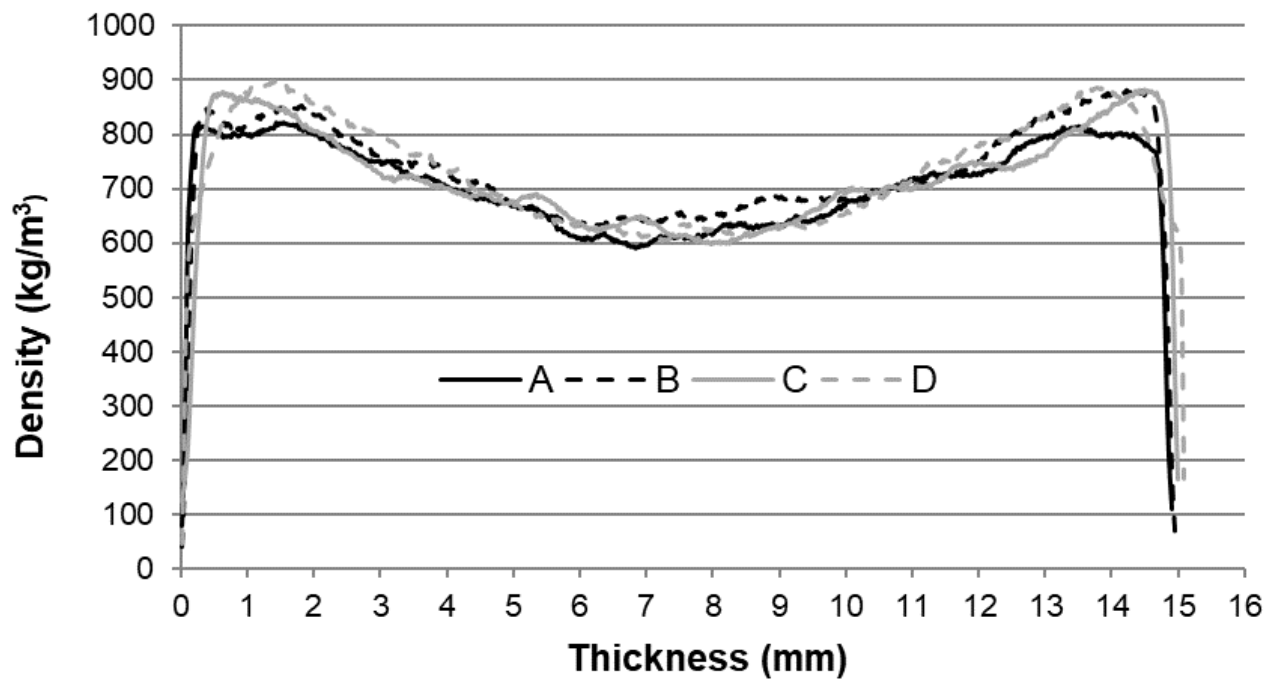

Fig. 1. Density profiles of tested panels 
Wood-polymer composites manufactured with the contribution of a thermoplastic (variants $\mathrm{A}, \mathrm{B}$, and $\mathrm{C}$ ) were characterized by a significant decrease in MOR and MOE values when compared to the control variant (option D) (Table 4). The decrease in panel strength of panels with thermoplastic was 25 to $28 \%$ in the case of MOR and 52 to $65 \%$ in MOE (Table 4). According to Falk's study (1999), WPC composites with $20 \%$ and $60 \%$ wood flour content have lower MOR and MOE values than traditional wood-based materials. At the same time, the authors indicated that WPC composites achieve comparable values of tensile and compressive strength as well as hardness in comparison to traditional wood materials. Sellers (2000) obtained similar strength properties to particleboards by examining flat-pressed boards of wood fibers and kenaf bonded with polyethylene or polystyrene (wood per polymer content was $50 \%$ per $50 \%$ ) with densities of 600 to $900 \mathrm{~kg}$ per $\mathrm{m}^{3}$.

Table 4. MOR, MOE, and IB values of the Tested Panels

\begin{tabular}{|c|c|c|c|c|c|c|}
\hline \multirow{2}{*}{ Variant } & \multicolumn{2}{|c|}{ MOR $\left(\mathrm{N}\right.$ per $\left.\mathrm{mm}^{2}\right)$} & \multicolumn{2}{c|}{ MOE $\left(\mathrm{N}\right.$ per $\left.\mathrm{mm}^{2}\right)$} & \multicolumn{2}{c|}{ IB $\left(\mathrm{N}\right.$ per $\left.\mathrm{mm}^{2}\right)$} \\
\cline { 2 - 7 } & Avg. & St. Dev. & Avg. & St. Dev. & Avg. & St. Dev. \\
\hline D & $13.55^{\mathrm{a}}$ & 0.95 & $2309^{\mathrm{a}}$ & 135 & $0.88^{\mathrm{a}}$ & 0.07 \\
\hline A & $9.94^{\mathrm{b}}$ & 0.98 & $1110^{\mathrm{b}}$ & 113 & $0.81^{\mathrm{a}}$ & 0.07 \\
\hline B & $10.17^{\mathrm{b}}$ & 0.90 & $1009^{\mathrm{b}}$ & 72 & $0.85^{\mathrm{a}}$ & 0.08 \\
\hline C & $9.73^{\mathrm{b}}$ & 0.50 & $807^{\mathrm{c}}$ & 68 & $0.88^{\mathrm{a}}$ & 0.08 \\
\hline
\end{tabular}

*Note: abc is the homogeneous groups by the Tukey test with a equal to 0.05 , Avg. is the average value, and St. Dev. is the standard deviation.

\section{Table 5. SH Values of the Tested Plates}

\begin{tabular}{|c|c|c|c|c|}
\hline \multirow{2}{*}{ Variant } & \multicolumn{2}{|c|}{$\mathrm{SH}^{\perp *}(\mathrm{~N}$ per mm) } & \multicolumn{2}{c|}{$\mathrm{SH}^{*}(\mathrm{~N}$ per mm $)$} \\
\cline { 2 - 5 } & Avg. & St. Dev. & Avg. & St. Dev. \\
\hline D & $82.12^{\mathrm{a}}$ & 8.31 & $55.00^{\mathrm{a}}$ & 6.44 \\
\hline A & $82.76^{\mathrm{a}}$ & 8.89 & $51.70^{\mathrm{a}}$ & 4.54 \\
\hline B & $71.76^{\mathrm{b}}$ & 7.55 & $39.86^{\mathrm{c}}$ & 3.57 \\
\hline C & $77.12^{\mathrm{ab}}$ & 6.80 & $44.33^{\mathrm{b}}$ & 4.91 \\
\hline
\end{tabular}

*Note: abc is the homogeneous groups by the Tukey test with $\alpha$ equal to $0.05, \perp$ means perpendicular to the surface, II means parallel to the surface, Avg. is the average value, and St. Dev. is the standard deviation.

The tested wood-polymer composites were characterized by similar IB values (insignificant differences) in relation to the control particleboards (variant D). The decrease in MOR and MOE values was an outcome of polyethylene presence in the face layers. Polyethylene is a material with much lower elastic properties than wood (Seachtling and Woebcken 1995).

The increase in thermoplastic content in the face layers from $40 \%$ (variant A) to $60 \%$ (variant C) did not have a significant effect on the MOR properties (Table 5). However, a significant decrease by approximately $20 \%$ in MOE values was observed when the thermoplastic content in the face layers increased from $50 \%$ (variant B) to $60 \%$ (variant C). The obtained dependencies corresponded to the data presented in the literature. Stark and Berger (1997), Błędzki and Faruk (2004), Lee et al. (2004), or Cui et al. (2008) reported that as the content of wood particles in the composite decreases (regardless of their size), the MOR and MOE values decrease, whereas the tensile strength increases.

The produced wood-polymer composites (variant A, B, and C) when compared to 
the control particleboards (variant D) were characterized by a decrease in SH values both in the perpendicular and parallel tests (Table 5). However, it should be noted that in the case of SH in the perpendicular system, the registered differences were insignificant (Table 5). In the parallel system, the maximum decrease of $28 \%$ in the $\mathrm{SH}$ value was recorded for variant $\mathrm{B}$. The literature report that $\mathrm{SH}$ in the WPC composites is comparable or higher than in solid wood or wood-based materials (Falk et al. 1999; Carroll et al. 2001; Kociszewski et al. 2007; Gozdecki and Kociszewski 2008). However, the literature data related mostly to extruded composites, which have a more even and uniform internal structure in comparison to the analyzed panels produced by pressing. It is also important to note that the obtained $\mathrm{SH}$ values for the tested wood-polymer composites were in the range of values provided among others for traditional particleboard (30 to $75 \mathrm{~N}$ per $\mathrm{mm}$ ) (Niemz and Sonderegger 2017).

The produced particle-polymer boards compared to the control particle boards were characterized by much higher moisture resistance. The decrease in TS (soaking after 2 and $24 \mathrm{~h}$ ) was in the range of $74 \%$ to $86 \%$, while the decrease in absorptivity (after 2 and $24 \mathrm{~h}$ of soaking) was between $58 \%$ and $64 \%$.

Table 6. Physical Properties of the Tested Panels

\begin{tabular}{|c|c|c|c|c|c|c|c|c|}
\hline \multirow{2}{*}{ Variant } & \multicolumn{2}{|c|}{ TS 2 $(\%)$} & \multicolumn{2}{c|}{ TS 24 h (\%) } & \multicolumn{2}{c|}{ WA $^{*} 2 \mathrm{~h}(\%)$} & \multicolumn{2}{c|}{ WA $^{*} 24 \mathrm{~h}(\%)$} \\
\cline { 2 - 9 } & Avg. & St. Dev. & Avg. & St. Dev. & Avg. & St. Dev. & Avg. & St. Dev. \\
\hline D & $25.39^{\mathrm{a}}$ & 1.87 & $29.95^{\mathrm{a}}$ & 2.29 & $76.29^{\mathrm{a}}$ & 3.88 & $91.75^{\mathrm{a}}$ & 3.73 \\
\hline A & $5.88^{\mathrm{b}}$ & 0.51 & $7.80^{\mathrm{b}}$ & 0.49 & $29.63^{\mathrm{b}}$ & 2.30 & $38.22^{\mathrm{b}}$ & 2.51 \\
\hline B & $5.10^{\mathrm{b}}$ & 0.33 & $6.75^{\mathrm{b}}$ & 0.48 & $29.31^{\mathrm{b}}$ & 1.70 & $37.09^{\mathrm{b}}$ & 1.95 \\
\hline C & $3.43^{\mathrm{c}}$ & 0.23 & $4.91^{\mathrm{c}}$ & 0.47 & $27.26^{\mathrm{b}}$ & 1.73 & $33.55^{\mathrm{c}}$ & 2.07 \\
\hline
\end{tabular}

${ }^{*}$ Note: abc is the homogeneous groups by the Tukey test with a equal to 0.05 , Avg. is the average value, and St. Dev. is the standard deviation.

The high resistance of WPC composites to water in relation to other wood-based panels is also confirmed by the literature data (Falk et al. 1999; Sellers et al. 2000). Synthetic polymers in general have low water absorption (less than 1\%) (Saechtling 2000) and act as a hydrophobic agent in WPC composites. They mechanically block the access of moisture to wood particles in the composite. Hydrophobic properties deteriorate with the increase in the contribution of wood particles in the composite (Zajchowski et al. 2005) and the increase in the porosity of its structure.

The increase in the thermoplastic content in the face layers from $40 \%$ (variant A) to $60 \%$ (variant B) reduced the penetration of moisture into the structure of the boards (significant decrease in swelling and water absorption) (Table 6). This is a favorable effect, if one assumes the use of the composite in an environment with a high relative humidity (e.g., as elements of bathroom furniture).

\section{Susceptibility to Drilling and Milling}

The produced wood-polymer composites (variants A, B, and C) compared to the control particleboards (variant D) were easier to process. Both axial forces during drilling (Fig. 2) and the resultant cutting forces during milling (Fig. 3) were approximately 10 to $20 \%$ lower than the forces recorded during the processing of the control particleboards. A significant decrease in axial forces was noted for drilling (variants B and C). Better machinability of the particleboard with thermoplastic in terms of cutting resistance reported Wilkowski et al. (2013). Zbieć et al. (2010) examining the parameters of the WPC board 
cutting process (30\% polyethylene) found that they are comparable to cutting parameters of particleboards with similar densities and glued with a UF resin. At the same time, the polyethylene that was part of the wood-polymer composite affected tool wear approximately 10 times slower compared to the traditional particleboard.

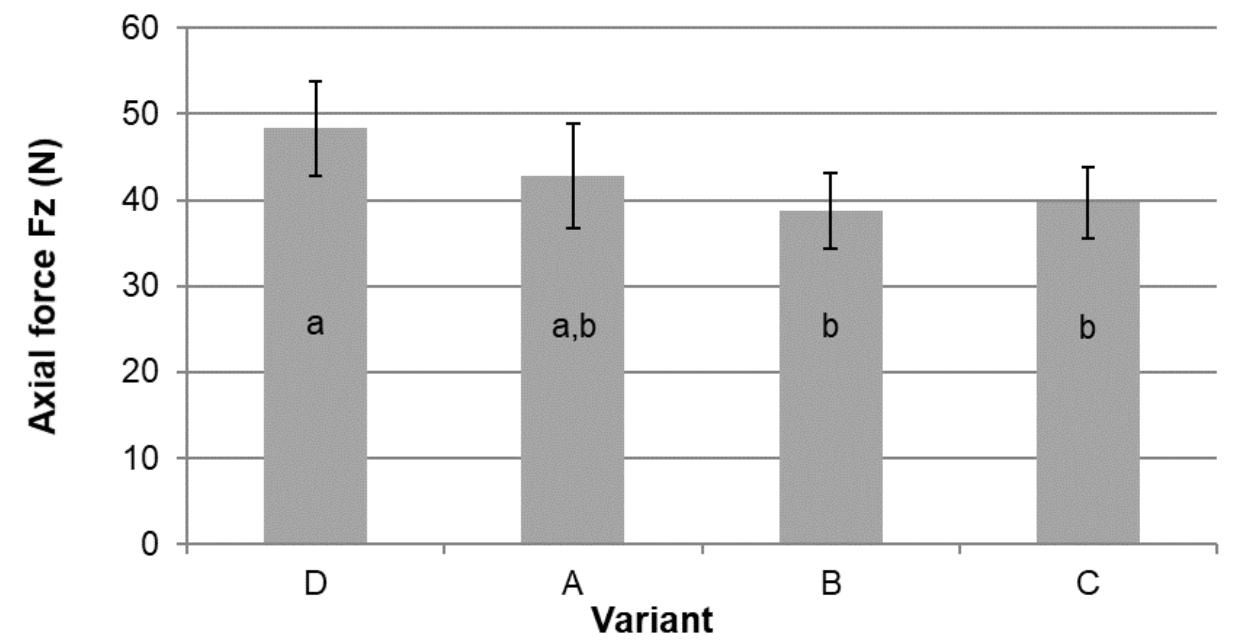

Fig. 2. Axial force values during plate drilling ( $a b$ is the homogeneous groups by the Tukey test)

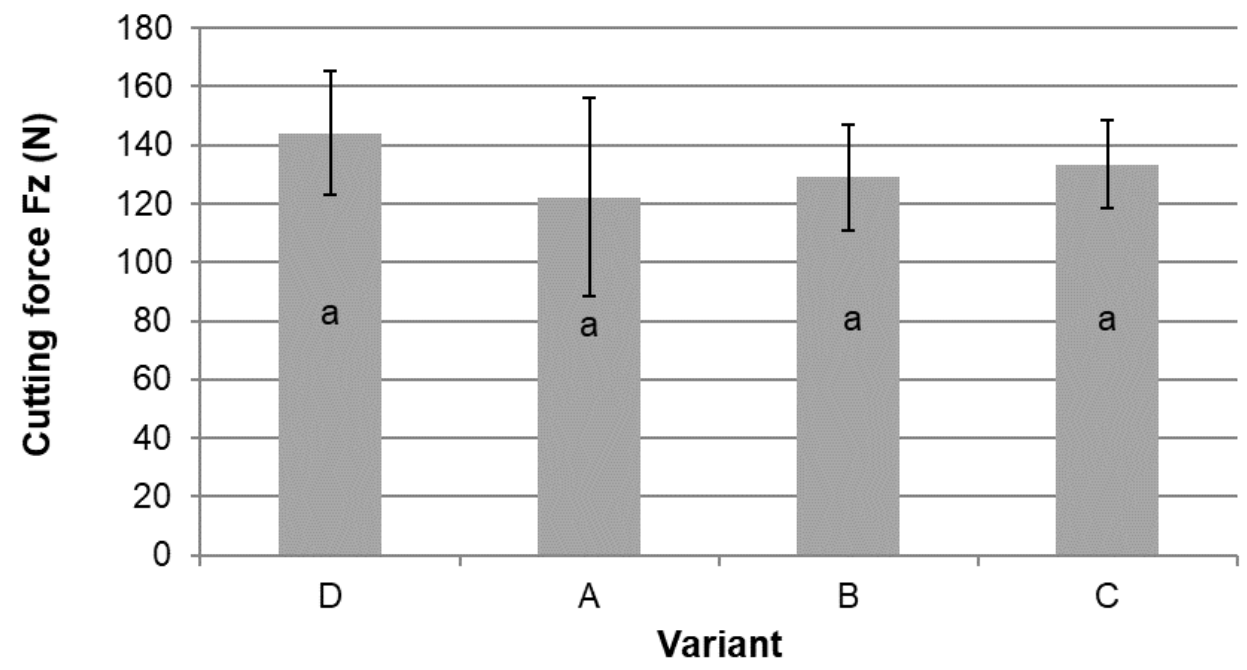

Fig. 3. Cutting force values $(F w)$ when milling boards (a represents the homogeneous groups by the Tukey test)

Buchlmann et al. (2001) reported that increased pigmentation of WPC composites may promote wear of cutting tools. In the present experiment, an increase in polyethylene content in face layers ranging from 40 to $60 \%$ did not significantly affect the values of the tested forces (Fig. 3).

\section{Contact Angle and Surface Free Energy}

The tested wood-polymer composites were characterized by reduced surface wettability (greater hydrophobicity). Regardless of the thermoplastic contribution in the face layers (variants A, B, C), the average contact angles of the surface with water were 
from $42 \%$ to $48 \%$ larger than the average contact angle of the control boards (option D) (Table 7). At the same time, wood-polymer composites presented $25 \%$ to $28 \%$ lower free surface energy (Table 7). Wettability is crucial with respect to the gluing process and surface finishing. The reduced wettability in variants $\mathrm{A}, \mathrm{B}$, and $\mathrm{C}$ impedes covering the surfaces with an aqueous solution (e.g., glue or paint), and on the other hand, it decreases the penetration of moisture it the control board (variant D). According to literature data, contact angles below $90^{\circ}$ indicate good wetting of the surface by the liquid (Baharoğlu et al. 2012). Buyuksari et al. (2010), Baharoğlu et al. (2012), and Sari et al. (2013) reported that contact angles for various particleboard variants are in the range of $83^{\circ}$ to $116^{\circ}$. In turn, Ayrilmiss et al. (2012) found that the contact angles of the surface of flat WPC composites (depending on the size and content of wood particles, density of composites, and pressing temperature) were in the range of $70.9^{\circ}$ to $102.4^{\circ}$. Jaunslavietis et al. (2018) indicated that the free surface energy of WPC composites made based on polypropylene with the participation of $50 \%$ wood particles is below $30 \mathrm{mN}$ per $\mathrm{m}$. In general, it can be stated that all tested wood-polymer composites (variants $\mathrm{A}, \mathrm{B}$, and $\mathrm{C}$ ) revealed comparable or better surface wettability (smaller contact angle and higher free surface energy) in reference to data presented in the literature.

Table 7. Value of Contact Angle and Surface Free Energy

\begin{tabular}{|c|c|c|c|c|c|}
\hline \multirow{3}{*}{ Variant } & \multicolumn{4}{|c|}{ Wettability (contact angle $\left.{ }^{\star}\right)\left(^{\circ}\right)$} & \multirow{3}{*}{$\begin{array}{c}\text { Surface free } \\
\text { energy** } \\
(\mathrm{mN} / \mathrm{m})\end{array}$} \\
\hline & \multicolumn{2}{|c|}{ Water } & \multicolumn{2}{|c|}{ Diiodomethane } & \\
\hline & Avg. & St. Dev & Avg. & St. Dev. & \\
\hline $\mathrm{D}$ & $55,66^{a}$ & 11,2 & $30,87^{a}$ & 2,1 & 57,12 \\
\hline$A$ & $82,29^{b}$ & 6,6 & $38,39^{a b}$ & 3,5 & 43,04 \\
\hline B & $79,96^{b}$ & 6,4 & $43,39^{a b}$ & 7,2 & 41,71 \\
\hline C & $79,20^{\mathrm{b}}$ & 3,8 & $45,74^{b}$ & 7,6 & 41,00 \\
\hline
\end{tabular}

${ }^{*}$ Note: the contact angle was determined for $2 \mathrm{~s}$, while in the subsequent seconds the drop completely dispersed, and the ** surface energy was calculated by the Owens-Wendt method.

$\mathrm{ab}$ is the homogeneous groups determined by the Tukey test with a equal to 0.05 , Avg. is the average value, and St. Dev. is the standard deviation.

\section{Resistance to Mold}

The tested wood-polymer composites exhibited higher resistance to mildew (Fig. 4). The result of mold growth on the samples surface is illustrated in Fig. 5. Schirp et al. (2008) reported that WPC is susceptible to mold fungi. However, there is a lack of detailed information on this subject in the literature. Variant A of the wood-polymer composites (with a $40 \%$ thermoplastic content in the face layers) indicated a $25 \%$ lower tendency to surface fouling in comparison to the control samples (variant D). An increase in thermoplastic content in the face layers of up to $50 \%$ (variant B) increased the rate of growth of mold by 3.5-fold. In the case of wood-polymer composites (variant C), only 64\% of the samples surface was covered after 22 days of exposure to the Trichoderma virens mold fungi (Fig. 4). Vidholdová et al. (2015) reported that traditional particleboard with uncovered surfaces are easily overgrown by mold fungi. WPCs with larger wood particles and their greater contribution are more susceptible to mold fungi (Schirp et al. 2008; Kartal et al. 2013; Feng et al. 2014). WPC susceptibility to molding is also dependent on the species of wood used as the filler (Feng et al. 2016). Klyosov (2007) reported that mold fungi reduce the aesthetics of WPC products by changing their color and decomposition. They also have a harmful effect on human and animal health (Jaakkola et al. 2013; Hernberg et al. 2014). 


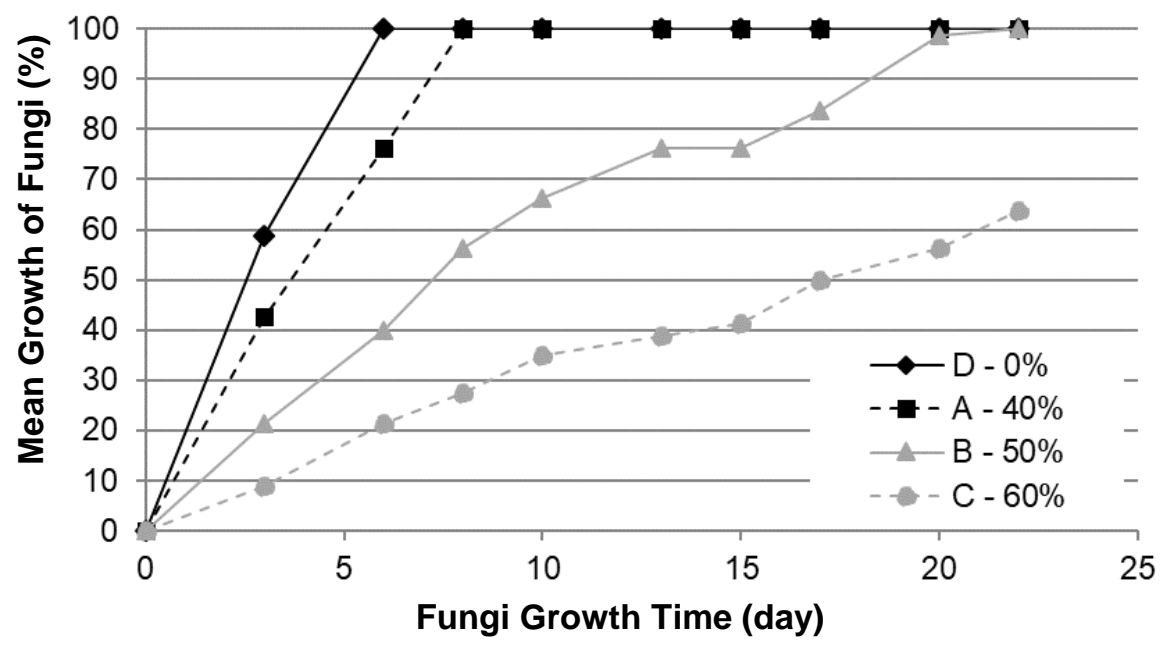

Fig. 4. Trichoderma virens mold fungal surface growth rate

Schirp et al. (2008) reported that the effect of staining fungi and mold fungi on WPC has been characterized only by the method of visual evaluation of microbial growth on the material. In this research, a computer analysis was carried out for the mold growth image on the samples surface.

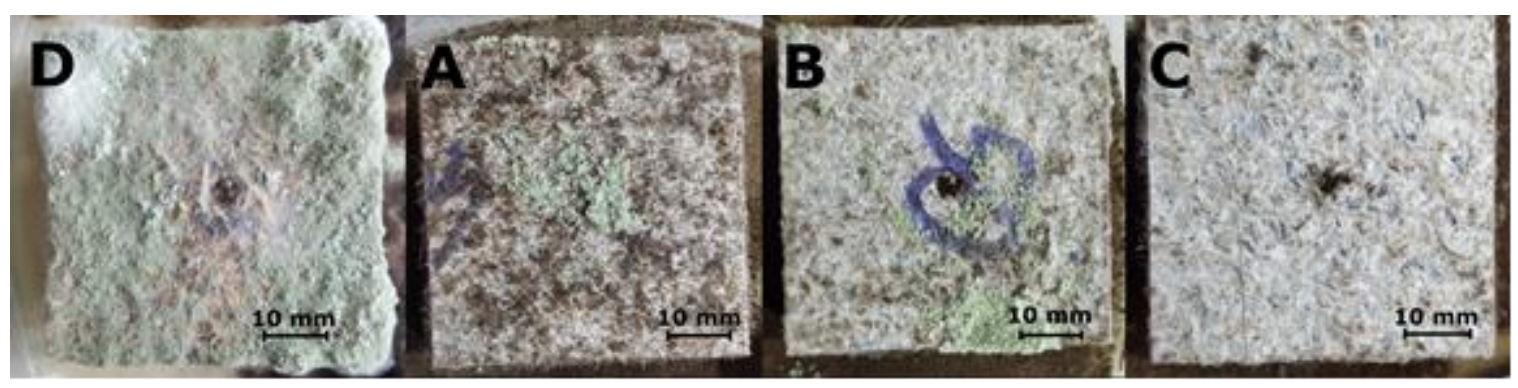

Fig. 5. Images of panel samples after 22 days of exposure to Trichoderma virens molds

\section{CONCLUSIONS}

1. Flat pressed wood-polymer composites combine selected properties of both traditional particleboard and WPC. In comparison to particleboard, wood-polymer composites present lower MOR and MOE values, but similar IB and SH values.

2. Wood-polymer composites are easier to machine (drilling and milling) than traditional particleboard.

3. Wood-polymer composites characterized high moisture resistance and the associated dimensional stability.

4. The composites indicated increased hydrophobicity of the surface, but simultaneously revealed a high wettability (contact angle below $90^{\circ}$ ) that should not unduly hinder the finishing process.

5. Although the wood-polymer composites presented high resistance to mold fungi, the 
resistance increased as the thermoplastic content in the face layers increased.

6. The tested panels can be used in conditions of increased humidity, e.g., as bathroom furniture elements.

\section{ACKNOWLEDGMENTS}

The presented research was financed under the "Strategic research and development program: environment, agriculture, and forestry" (BIOSTRATEG, Grant No. BIOSTRATEG3/344303/14/NCBR/2018). The funding institution was The National Centre for Research and Development

\section{REFERENCES CITED}

Ayrilmişs, N., Benthien, J. T., and Thoemen, H. (2012). "Effects of formulation variables on surface properties of wood plastic composites," Compos. Part B-Eng. 43(2), 325331. DOI: 10.1016/j.compositesb.2011.07.011

Baharoğlu, M., Nemli, G., Sari, B., Bardak, S., and Ayrilmiş, N. (2012). "The influence of moisture content of raw material on the physical and mechanical properties, surface roughness, wettability, and formaldehyde emission of particleboard composite," Compos. Part B-Eng. 43(5), 2448-2451. DOI: 10.1016/j.compositesb.2011.10.020

Barton-Pudlik, J., Czaja, K., Grzymek, M., and Lipok, J. (2017). "Evaluation of woodpolyethylene composites biodegradability caused by filamentous fungi," Int. Biodeterior. Biodegr. 118, 10-18. DOI: 10.1016/j.ibiod.2017.01.014

Błędzki, A. K., and Faruk, O. (2004). "Wood fiber reinforced polypropylene composites: Compression and injection molding process," Polym. - Plast. Technol. 43(3), 871888. DOI: $10.1081 /$ PPT-120038068

Boeglin, N., Triboulot, P., and Masson, D. (1997). "A feasibility study on boards from wood and bending properties, dimensional stability," Holz als Roh- und Werkstoff (1997) 55, 13. DOI: 10.1007/s001070050217

Borysiuk, P. (2004). "Die Anwendung den thermoplastischen Kunststoffabfälle zur Spanplatten- und Sperrholzherstellung [The use of thermoplastics for the particleboard and plywood production]," Ann Warsaw Agric. Univ. For Wood Technol. 55, 50-56.

Borysiuk, P., Mamiński, M. Ł., Nicewisz, D., Boruszewski, P., and Zado, A. (2008). "Waste thermoplastics as binder for green and recycled wood bonding in particleboard manufacturing Mater. Z," Int. Panel Prod. Symp. Dipoli Conf. Centre, 249-254.

Borysiuk, P., Nicewicz, D., and Pawlicki, J. (2004). "Wood-based materials utilizing waste thermoplastics," in: Vth International Symposium: Composite Wood Materials 2004, Zborník referátov, Zvolen, pp. 119-124.

Borysiuk, P., Pawlicki, J., and Nicewicz, D. (2006). "New types of raw materials in technologies of wood-based materials," in: Materiaty z konferencji COST Action E44 - E49, Wood Resources and Panel Properties, Valencia, Spain, pp. 277-281.

Buchlmann, U., Saloni, D., and Lemaster, R. L. (2001). "Wood fiber-plastic composites: 
Machining and surface quality," in: The 15th International Wood Machining Seminar, Anaheim, CA, pp. 1-13.

Buyuksari, U., Avci, E., Ayrilmis, N., and Akkilic, H. (2010). "Effect of pinecone ratio on the wettability and surface roughness of particleboard," BioResources 5(3), 18241833. DOI: 10.15376/biores.5.3.1824-1833

Carroll, D. R., Stone, R. B., Sirignano, A. M., Saindon, R. M., Gose, S. C., and Friedman, M. A. (2001). "Structural properties of recycled plastic/sawdust lumber decking planks," Resour. Conserv. Recy. 31(3), 241-251. DOI: 10.1016/S09213449(00)00081-1

Chen, H. C., Chen, T. Y., and Hsu, C. H. (2006). "Effects of wood particle size and mixing ratios of HDPE on the properties of the composites," Holz Als Roh - Und Werkst 64(3), 172-177. DOI: 10.1007/s00107-005-0072-x

Cui, Y., Lee, S., Noruziaan, B., Cheung, M., and Tao, J. (2008). "Fabrication and interfacial modification of wood/recycled plastic composite materials," Compos. Part A-Appl. Sci. 39(4), 655-661. DOI: 10.1016/j.compositesa.2007.10.017

Djiporovic, M., Miljkovic, J., and Dingova, E. (2006). "On engineering of properties of wood-polypropylene composite," Glas ?Umarskog Fak 93(93), 59-70. DOI: $10.2298 / \mathrm{gsf0693059d}$

EN 310 (1994). "Wood-based panels - determination of modulus of elasticity in bending and of bending strength," European Committee for Standardization, Brussels, Belgium.

EN 317 (1999). "Particleboards and fiberboards - determination of swelling in thickness after immersion in water," European Committee for Standardization, Brussels, Belgium.

EN 319 (1999). "Particleboards and fiberboards - determination of tensile strength perpendicular to the plane of the board," European Committee for Standardization, Brussels, Belgium.

EN 320 (2011). "Particleboards and fiberboards - determination of resistance to axial withdrawal of screws," European Committee for Standardization, Brussels, Belgium.

EN 323 (1999). "Wood-based panels - determination of density," European Committee for Standardization, Brussels, Belgium.

Falk, R. H., Vos, D., and Cramer, S. M. (1999). "The comparative performance of woodfiber-plastic and wood-based panels," (https://www.fpl.fs.fed.us/documnts/pdf1999/falk99f.pdf), Accessed 21 Jan 2020.

Feng, J., Shi, Q., Chen, Y., and Huang, X. (2014). "Mold resistance and water absorption of wood/HDPE and bamboo/HDPE composites," J. Appl. Sci. 14(8), 776-783. DOI: 10.3923/jas.2014.776.783

Feng, J., Zhang, H., He, H., Huang, X., and Shi, Q. (2016). "Effects of fungicides on mold resistance and mechanical properties of wood and bamboo flour/high-density polyethylene composites," BioResources 11(2), 4069-4085. DOI: 10.15376/biores.11.2.4069-4085

Gozdecki, C., and Kociszewski, M. (2008). "Study of the screw withdrawal capacity in wood-polymer composites exposed to the accelerated ageing process," Ann Warsaw Agric. Univ. For Wood Technol. 65, 84-87.

Hernberg, S., Sripaiboonkij, P., Quansah, R., Jaakkola, J. J. K., and Jaakkola, M. S. (2014). "Indoor molds and lung function in healthy adults," Resp. Med. 108(5), 677684. DOI: 10.1016/j.rmed.2014.03.004

Jaakkola, M. S., Quansah, R., Hugg, T. T., Heikkinen, S. A. M., and Jaakkola, J. J. K. 
(2013). "Association of indoor dampness and molds with rhinitis risk: A systematic review and meta-analysis," J. Allergy Clin. Immun. 132(5), 1099-1110. DOI: 10.1016/j.jaci.2013.07.028

Jaunslavietis, J., Shulga, G., Ozolins, J., Neiberte, B., Verovkins, A., Vitolina, S., and Betkers, T. (2018). "Hydrophilic-hydrophobic characteristics of wood-polymer composites filled with modified wood particles," Key Eng. Mater. 762, 176-181. DOI: 10.4028/www.scientific.net/KEM.762.176

Kartal, S. N., Aysal, S., Terzi, E., Yilgör, N., Yoshimura, T., and Tsunoda, K. (2013). "Wood and bamboo-PP composites: Fungal and termite resistance, water absorption, and FT-IR analyses," BioResources 8(1), 1222-1244. DOI: 10.15376/biores.8.1.12221244

Klyosov, A. A. (2007). Wood-Plastic Composites, John Wiley \& Sons, Inc., Hoboken, New Jersey.

Kociszewski, M., Gozdecki, C., Zajchowski, S., and Mirowski, J. (2007). "Screw withdrawal strength of WPC made by injection molding method," Ann Warsaw Agric. Univ. For Wood Technol. 61, 336-339.

Lee, S. Y., Yang, H. S., Kim, H. J., Jeong, C. S., Lim, B. S., and Lee, J. N. (2004). "Creep behavior and manufacturing parameters of wood flour filled polypropylene composites," Compos. Struct. 65(3-4), 459-469. DOI:

10.1016/j.compstruct.2003.12.007

Lyutyy, P., Bekhta, P., and Ortynska, G. (2018). "Lagane drvno-plastične kompozitne ploče: Mogućnost proizvodnje i svojstva [Lightweight flat pressed Wood Plastic Composites: possibility of manufacture and properties]," Drv. Ind. 69, 55-62. DOI: 10.5552/drind.2018.1746

Niemz, P., and Sonderegger, W. (2017). Holzphysik: Physik des Holzes und der Holzwerkstoffe [Wood physics: Physics of wood and wood-based materials], Carl Hanser Verlag GmbH \& Co. KG., München. DOI: 10.3139/9783446445468

Owens, D. K., and Wendt, R. C. (1969). "Estimation of the surface free energy of polymers," J. Appl. Polym. Sci. 13(8), 1741-1747. DOI: 10.1002/app.1969.070130815

Rahman, K.S., Islam, M.N., Rahman, M.M., Hannan, M.O., Dungani, R., and Abdul Khalil, H. P. S. (2013). "Flat-pressed wood plastic composites from sawdust and recycled polyethylene terephthalate (PET): Physical and mechanical properties," Springerplus 2, Article number 629. DOI: 10.1186/2193-1801-2-629

Seachtling, H., and Woebcken, W. (1995). International Plastics Handbook 3rd edition, Hanser Gardner Publications, Cincinnati, OH.

Sari, B., Nemli, G., Ayrilmis, N., Baharoğlu, M., and Bardak, S. (2013). "The influences of drying temperature of wood particles on the quality properties of particleboard composite," Dry. Technol. 31(1), 17-23. DOI: 10.1080/07373937.2012.711791

Schindelin, J., Arganda-Carreras, I., Frise, E., Kaynig, V., Longair, M., Pietzsch, T., and Cardona, A. (2012). "Fiji: An open-source platform for biological-image analysis," Nat. Methods 9, 676-82. DOI: 10.1038/nmeth.2019

Schirp, A., Ibach, R. E., Pendleton, D. E., and Wolcott, M. P. (2008). "Biological degradation of wood-plastic composites (WPC) and strategies for improving the resistance of WPC against biological decay," ACS Symposium Series 982, 480-507. DOI: 10.1021/bk-2008-0982.ch029

Sellers, T., Miller, G. D., and Katabian, M. (2000). "Recycled thermoplastics reinforced with renewable lignocellulosic materials," Forest Prod. J. 50(5), 24-28. 
Stark, N. M., and Berger, M. J. (1997). "Effect of species and particle size on properties of wood-flour-filled polypropylene composites," (https://pdfs.semanticscholar.org/9011/db0f78822ad3c345ccd7cc6af8fb584eab00.pdf ), Accessed 21 Jan 2020.

Thoemen, H., Irle, M., and Sernek, M. (2010). Wood-Based Panels: An Introduction for Specialists, Brunel University Press, London.

Tinevez, J. Y., Perry, N., Schindelin, J., Hoopes, G. M., Reynolds, G. D., Laplantine, E., and Eliceiri, K. W. (2017). "TrackMate: An open and extensible platform for singleparticle tracking," Methods 115, 80-90. DOI: 10.1016/j.ymeth.2016.09.016

Treusch, O., Tröger, F., and Wegener, G. (2004). "Einfluss von Rohdichte und Bindemittelmenge auf das Rohdichteprofil von einschichtigen Spanplatten [The influence of apparent density and adhesive content on the density profile of singlelayer particleboards]," Holz Als Roh - Und Werkst 62(6), 474-475. DOI: 10.1007/S00107-004-0510-1

Verhey, S. A., and Laks, P. (2002). "Wood particle size affects the decay resistance of wood fiber / thermoplastic composites," Forest Prod. J. 52 (11/12), 78-81.

Vidholdová, Z., Iždinský, J., Reinprecht, L., and Krokošová, J. (2015). “Activity of bacteria and molds on surfaces of commercial wooden composites," Mater. Sci. Forum 818, 190-193. DOI: 10.4028/www.scientific.net/MSF.818.190

Wilkowski, J., Borysiuk, P., Górski, J., and Czarniak, P. (2013). "Analysis of relative machinability indexes of wood particle boards bonded with waste thermoplastics," Drewno Wood 190, 139-144. DOI: 10.12841/wood.1644-3985.039.09

Wolkenhauer, A., Avramidis, G., Hauswald, E., Militz, H., and Viöl, W. (2009). "Sanding vs. plasma treatment of aged wood: A comparison with respect to surface energy," Int. J. Adhes. Adhes. 29(1), 18-22. DOI: 10.1016/j.ijadhadh.2007.11.001

Wong, E. D., Zhang, M., Wang, Q., and Kawai, S. (1999). "Formation of the density profile and its effects on the properties of particleboard," Wood Sci. Technol. 33(4), 327-340. DOI: 10.1007/s002260050119

Wong, E. D. (1998). "Effects of mat moisture content and press closing speed on the formation of density profile and properties of particleboard," J. Wood Sci. 44(4), 287295. DOI: 10.1007/BF00581309

Wong, E. D., Yang, P., Zhang, M., Wang, Q., Nakao, T., Li, K. F., and Kawai, S. (2003) "Analysis of the effects of density profile on the bending properties of particleboard using finite element method (FEM)," Holz Als Roh - Und Werkst 61(1), 66-72. DOI: $10.1007 / \mathrm{s} 00107-002-0350-9$

Youngquist, J. A. (1995). "Unlikely partners? The marriage of wood and nonwood materials," Forest Prod. J. 45 (10), 25-30.

Youngquist, J. A., Myers, G. E., Muehl, J. H., Krzysik, A. M., and Clemons, C. M. (1994). Composites from Recycled Wood and Plastics, U.S. Environmental Protection Agency, Forest Products Laboratory, Madison, WI.

Zajchowski, S., Gozdecki, C., and Kociszewski, M. (2005). "The investigation of physical and mechanical properties of wood plastic composites (WPC)," Kompozyty $5,45-50$. 
Zbieć, M., Borysiuk, P., and Mazurek, A. (2010). "Polyethylene bonded composite chipboard," in: Part 2 Machining Tests: Proceedings from the 7th International Science Chip and Chipless Woodworking Processes Conference 2010, Terchová, Slovak Republic, pp. 237-242.

Article submitted: March 17, 2020; Peer review completed: May 3, 2020; Revised version received and accepted: May 12, 2020; Published: May 15, 2020.

DOI: $10.15376 /$ biores. 15.3.5141-5155 